\title{
Thrombotic Occlusion of Bjork-Shiley Prosthetic Aortic Valve
}

\author{
Sumeesh Dhawan MD, Hospitalist, Marshfield Cinic, Marshfield, Wisconsin \\ Param Sharma MD, Department of Cardiology, Marshfield Cinic, Marshfield, Wisconsin \\ Tahir Tak, MD, PhD, Department of Cardiology, Marshfield Cinic, Marshfield, Wisconsin
}

\section{ABSTRACT}

Thrombotic occlusion of a prosthetic Bjork-Shiley valve is a potentially fatal complication. We present the case of a male, 62 years of age, diagnosed with thrombotic occlusion of prosthetic Bjork-Shiley aortic valve approximately 17 years post implantation. A brief review of the literature focusing on potential risk factors associated with the development of this condition and currently available diagnostic modalities used for evaluation and treatment are presented.

\section{INTRODUCTION}

Thrombosis of Bjork-Shiley valves results in occlusion of the prosthetic valve and is associated with high morbidity and mortality. It may also present as congestive heart failure. We report a case of a male, 62 years of age, admitted to a tertiary care center with similar complications.

REPRINT REQUESTS:

Tahir Tak, MD, PhD

Department of Cardiology

Marshfield Clinic

1000 North Oak Avenue

Marshfield, WI 54449

Telephone: 715-387-5301

Fax: 715-389-4555

Email: tak.tahir@marshfieldclinic.org
KEYWORDS:

Bjork-Shiley valve; Thrombosis; Valve prosthesis 


\section{CASE REPORT}

In 1985, a male, 62 years of age, underwent aortic and mitral valve replacement with Bjork-Shiley prostheses (both $27 \mathrm{~mm}$ ) for rheumatic heart disease. In 1986 he suffered significant brain trauma in a motor vehicle accident. As a result, there was significant impairment in cognitive and adaptive abilities with memory loss, psychomotor retardation and impaired problem-solving skills. In 2001 he was admitted to another institution for congestive heart failure. A two-dimensional echocardiogram was performed, which revealed no abnormality of the prosthetic aortic and mitral valves. There was bilateral atrial enlargement, left ventricular hypertrophy and pulmonary hypertension with Doppler derived pulmonary systolic pressure of $75 \mathrm{~mm} \mathrm{Hg}$.

He was readmitted in August 2002 for congestive heart failure. At that time a two-dimensional echocardiogram was performed that detected stenosis of the prosthetic aortic valve. He was subsequently transferred to our hospital, a tertiary care center.

On examination there was no jugular vein distension. Chest auscultation revealed bilateral posterior basilar rates. The carotid upstroke was normal. There was a grade $2 / 6$ systolic murmur in the lower sternal border. The opening and closing clicks of a prosthetic valve were faintly audible. There was bilateral pitting edema in the lower extremities.

The electrocardiogram showed atrial fibrillation with controlled ventricular response with right axis deviation. A chest $\mathrm{x}$-ray showed cardiomegaly with increasing parenchymal opacity in both lower sides, which may have represented pneumonitis, peribronchial edema, or atelectasis. The patient's international normalized ratio (INR) on admission was 3.9.

An emergent transthoracic echocardiogram was performed and demonstrated only partial opening of the prosthetic aortic disc. Color flow imaging showed crescent flow in systole. The peak instantaneous valve gradient was calculated to be $55 \mathrm{~mm} \mathrm{Hg}$. The prosthetic mitral valve appeared to be normal. Cinefluoroscopy of the Bjork-Shiley prosthetic valve revealed an open angle of $10^{\circ}$ (figures 1 and 2).

Thrombolytic therapy was considered to be contraindicated because of the patient's high INR. The remaining hospital course was complicated by cardiogenic shock with systolic blood pressure dropping to $70 \mathrm{~mm} \mathrm{Hg}$. There was also significant deterioration of renal function and mental faculties. A consultation with the cardiothoracic surgery team determined that the patient was a high-risk case for replacement of the stenotic prosthetic aortic valve. The patient died 5 days after admission.

\section{DISCUSSION}

A Bjork-Shiley valve is a tilting disc valve that uses a circular disc as an occluder and is retained by wire-like arms. To date approximately 360,000 standard valves have been implanted. However, in the United States, Bjork-Shiley
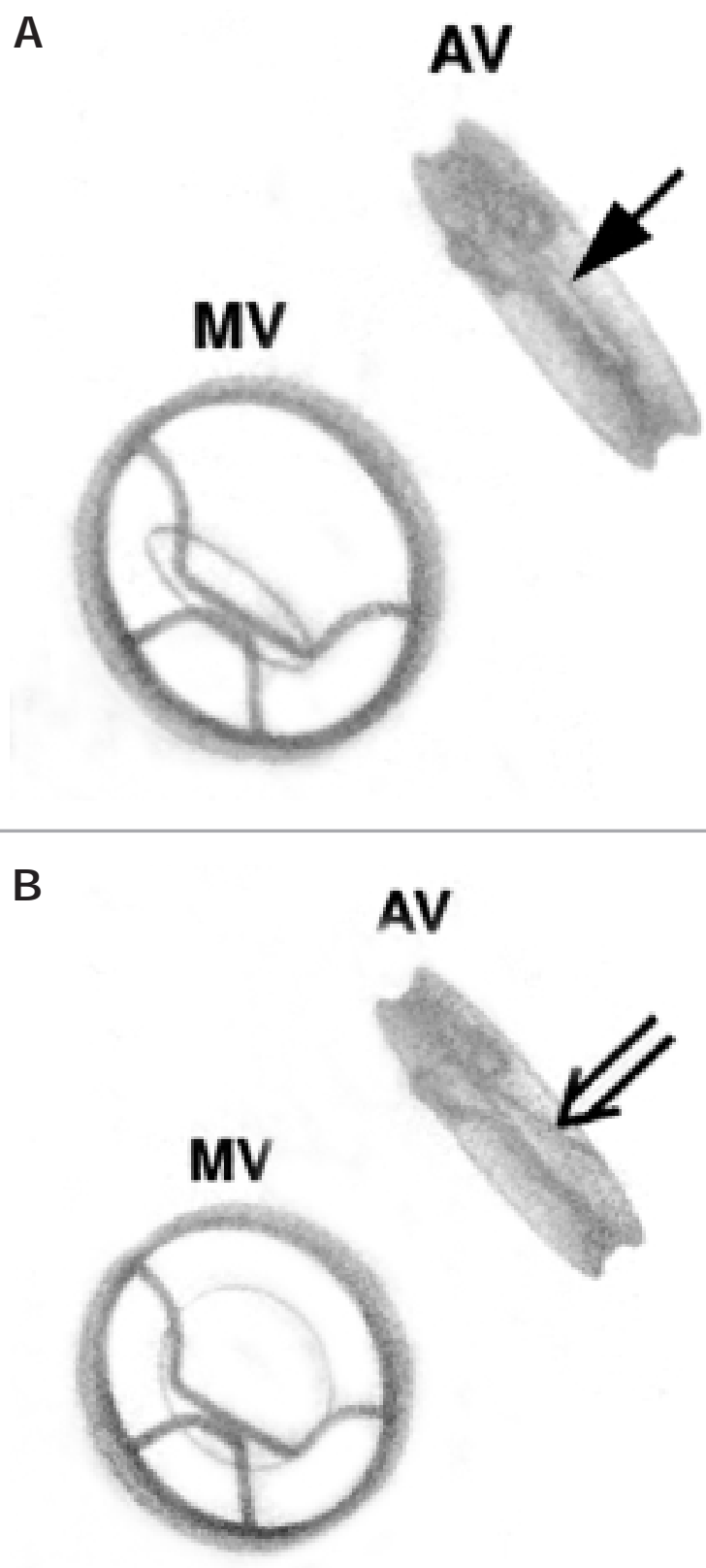

Figure 1. Images obtained by fluoroscopy. Arrow indicates closure (A) and opening (B) of the prosthetic aortic valve. The angle of opening was reduced to $10^{\circ}$ due to thrombosis.

models have been discontinued. Although they are no longer implanted in the United States, there are still many patients with Bjork-Shiley valves.

Thrombotic occlusion of prosthetic cardiac valves is considered one of the most serious complications associated with tilting disc mechanical valves. The overall risk of major thrombotic occlusion ranges from $1 \%$ to $8 \% .{ }^{1}$ Karp et al. estimated that the cumulative likelihood of thrombotic occlusion of Bjork-Shiley valve for aortic, mitral, and combination mitral and aortic levels is $3 \%, 13 \%$, and $13 \%$, respectively. ${ }^{2}$ The obstruction of prosthetic valve may be caused by thrombi formation, pannus ingrowth, or a combination of these. 


\section{Björk-Shiley Valve}

A

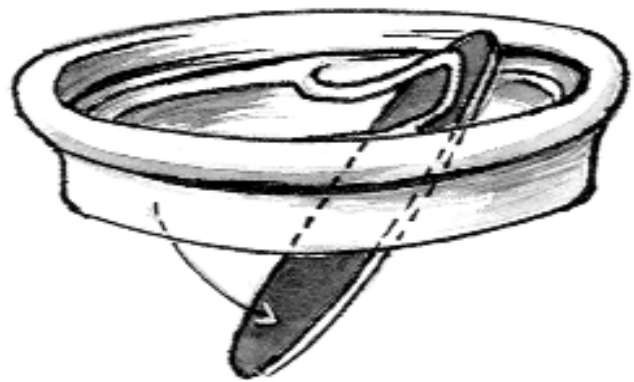

\section{Normal Valve (opening angle $=60^{\circ} \pm 2$ )}

B

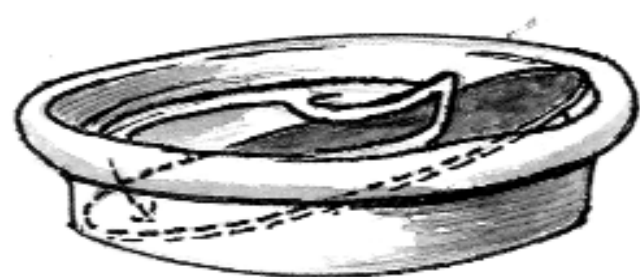

Thrombosed Valve (opening angle $\approx 10^{\circ}$ )

Figure 2. Schematic diagram of normal and thrombosed Bjork-Shiley prosthetic aortic valve end systolic excursion. The thrombosed valve in our patient opened approximately $10^{\circ}$ by fluoroscopy.

Reprinted with permission: Talley et al. Can J Cardiol 1986;2:152-155.

Thrombosis of prosthetic valves has been reported despite adequate anticoagulation. The risk of thrombosis is higher in prosthetic mitral valves than in prosthetic aortic valves. ${ }^{1-3}$ The factors that increase the risk of thrombosis are: ${ }^{3}$

- Inadequacy of anticoagulation,

- Design of valve,

- Pannus ingrowth,

- Orientation of minor orifice,

- Small valve size,

- Decreased cardiac output,

- Increased left atrial enlargement,

- Infective endocarditis.

Furthermore, the small size of the mitral annulus, decreased blood flow through the mitral valve, atrial fibrillation, left atrial enlargement and left atrial thrombosis at the time of valve replacement have all been associated with an increased risk of subsequent thrombosis of a prosthetic mitral valves. ${ }^{1}$

The single leaflet disc prosthesis has major and minor orifices. The blood flow through the minor orifice is roughly $23 \%$. This region is associated with decreased peak flow velocity and lower peak shear stress on the sewing rim of the Bjork-Shiley prosthesis. Which may result in pannus formation. ${ }^{4}$ Changing the disc to concavoconvex and the orientation of the prosthetic mitral valve posteriorly increases the blood flow through the minor orifice to $30 \%$. This reduces the risk of thrombosis. ${ }^{2,5}$

The initial suspicion for complications is based primarily on clinical history with subsequent confirmation by physical and laboratory examination. In a patient with new onset of congestive heart failure and nonimmunologic hematolytic anemia, attention should always be focused toward evaluation of prosthetic valves. ${ }^{6}$

The most helpful diagnostic feature on physical examination is the change in the intensity of opening and closing clicks of the valve. The presence of systolic and diastolic murmur is not an accurate indication of valve function. ${ }^{1}$ However, the clinical signs of valve incompetence and disappearance of the sound closure of the valve likely appear before the sign of prosthetic valve stenosis. ${ }^{7}$

The diagnosis can be made with cineradiography, echocardiography and cardiac catheterization. Discs of a Bjork-Shiley valve, manufactured after 1975, are incorporated with radio opaque markers. Therefore, cinefluoroscopy has played an important role as a diagnostic tool for the detection of prosthetic tilting disc valve dysfunction. The decrease in the angle of the disc (normal is $60^{\circ} \pm 2^{\circ}$ ) and immobility of the disc can be diagnosed with considerable accuracy. 1,7

Two-dimensional echocardiography and transesophageal echocardiography can show a density surrounding the valve and can also calculate the transvalvular gradient. Echocardiographic findings in patients with thrombotic occlusion of prosthetic valve include decreased amplitude of valve excursion, in conjunction with diminished opening and closing rates or absence of disc motion. ${ }^{8}$ A comparison study to the previous echocardiography, especially the change in time of valve opening and closure and chamber enlargement, is helpful. ${ }^{7}$ Besides accurately assessing stenosis and regeneration, cardiac catheterization may show a filling defect because of the thrombosis $1,7,9$ and an excessive pressure gradient across the prosthetic valve.

Thrombotic occlusion of the prosthetic aortic valve is a medical emergency. Thrombolytic therapy for an obstructed prosthetic valve is often ineffective, especially if it is caused by pannus ingrowth. The use of thrombolytic therapy is associated with a failure rate of $16 \%$ to $18 \%$ and an acute mortality rate of $6 \% .{ }^{10}$ Thrombolytic therapy should be reserved for those patients in whom either surgery is contraindicated or associated with higher risks. If possible, patients should undergo emergency exploratory cardiotomy. During cardiotomy, there are typically two options: either the debridement of the annulus of the prosthetic valve or the replacement of the prosthetic valve.

Re-operation of prosthetic valves have resulted in high mortality; $40 \%$ with valve replacement and $8 \%$ with thrombectomy and valve rotation. ${ }^{11-14}$ Replacement of prosthetic valve 
should be limited to cases of extensive, circular pannus underlying the thrombus-like material, or when the primary mechanical cause (i.e., disc wear, mobile module strut, irregular ring contour) is found. ${ }^{11}$

\section{CONCLUSION}

The diagnosis of thrombotic occlusion of Bjork-Shiley valve is suggested by clinical history and physical examination. High mortality rates associated with valve thrombosis are related to delays in diagnosis.

\section{ACKNOWLEDGMENTS}

The authors thank Marshfield Clinic Research Foundation for its support through the assistance of Linda Weis and Alice Stargardt in the preparation of this manuscript.

\section{REFERENCES}

1. Kontos GJ Jr, Schaff HV. Thrombotic occlusion of a prosthetic heart valve: diagnosis and management. Mayo Clin Proc 1985;60:118-122.

2. Karp RB, Cyrus RJ, Blackstone EH, Kirklin JW, Kouchoukos NT, Pacifico AD. The Bjork-Shiley valve: intermediate-term follow-up. J Thorac Cardiovasc Surg 1981;81:602-614.

3. Talley JD, Lutz JF, Wenger NK. Thrombotic occlusion of a Bjork-Shiley mitral valve. Can J Cardiol 1986;2:152-155.

4. Yoganathan AP, Corcoran WH, Harrison EC, Carl JR. The BjorkShiley aortic prosthesis: flow characteristics, thrombus formation and tissue overgrowth. Circulation 1978;58:70-76.

5. Bjork VO, Book K, Holmgren A. The Bjork-Shiley mitral valve prosthesis. A comparative study with different prosthesis orientations. Ann Thorac Surg 1974;18:379-390.

6. Comess KA, Fenster PE, Ewy GA, Copeland JG. Late thrombotic occlusion of a Bjork-Shiley valve producing hemolysis without hemodynamic compromise. Am Heart J 1981;101:112.

7. Moreno-Cabral RJ, McNamara JJ, Mamiya RT, Brainard SC, Chung GK. Acute thrombotic obstruction with Bjork-Shiley valves: diagnostic and surgical considerations. J Thorac Cardiovasc Surg 1978;75:321-330.

8. Fernandez J, Samuel A, Yang SS, Sumathisena Gooch A, Maranhao V, Lemole GM, Goldberg H. Late thrombosis of the aortic Bjork-Shiley prosthesis. Its clinical recognition and management. Chest 1976;70:12-16.

9. Kaul TK, Mercer JL. Combined mitral and aortic valve replacement with Bjork-Shiley prostheses: long term survival and valve-related complications. Thorac Cardiovasc Surg 1990;38:302-307.

10. Hurrell DG, Schaff HV, Tajik A. Thrombolytic therapy for obstruction of mechanical prosthetic valves. Mayo Clin Proc 1996;71:605-613.

11. Montero CG, Mula N, Brugos R, Tellez G, Figuera D. Thrombectomy of the Bjork-Shiley prosthetic valve revisited: long-term results. Ann Thorac Surg 1989;48:824-828.

12. Byrd CL, Yahr WZ, Greenberg JJ. Long-term results of "simple" thrombectomy for thrombosed Bjork-Shiley aortic valve prostheses. Ann Thorac Surg 1975;20:265-273.

13. Venugopal P, Kaul U, Iyer KS, Rao IM, Balram A, Das B, Sampathkumar A, Mukherjee S, Rajani M, Wasir HS, et al. Fate of thrombectomized Bjork-Shiley valves. A long-term cinefluoroscopic, echocardiographic, and hemodynamic evaluation. J Thorac Cardiovasc Surg 1986;91:168-173.

14. Gray LA Jr, Fulton RL, Srivastava TN, Flowers NC. Surgical treatment of thrombosed Bjork-Shiley aortic valve prosthesis. J Thorac Cardiovasc Surg 1976;71:429-432. 